\title{
Evaluation of the water sorption of luting cements in different solutions
}

\author{
Alma Gavranović-Glamoč ${ }^{1}$, Muhamed Ajanović ${ }^{1}$, Samra Korać ${ }^{2}$, Selma Zukićs, \\ Sanela Strujić-Porović ${ }^{1}$, Alma Kamber-Ćesir ${ }^{1}$, Lejla Kazazić ${ }^{1}$, Emir Berhamović ${ }^{1}$
}

${ }^{1}$ Department of Prosthodontics, Faculty of Dentistry with Clinics, University of Sarajevo, Bosnia and Herzegovina ${ }^{2}$ Department of Restorative Dentistry with Endodontics, Faculty of Dentistry with Clinics, University of Sarajevo, Bosnia and Herzegovina, ${ }^{3}$ Department of Dental Morphology, Anthropology and Forensics Faculty of Dentistry with Clinics University of Sarajevo

Correspondence:

alma.glamoc@gmail.com

Tel.: +38733214249

Fax: +38733443395

Received: 28 September 2017

Accepted: 29 November 2017

Key words: Water sorption - Resin modified cements $\boldsymbol{\bullet}$ Resin cements $\cdot$ Prosthodontics.

\begin{abstract}
Objective. To evaluate and compare the water sorption of three luting cements in three different solutions: distilled water and artificial saliva with different $\mathrm{pH}$ values (7.4 and 3.0). Materials and methods. Resin-modified glass-ionomer cement (GC Fuji Plus) and two resin cements (Multilink Automix and Variolink II) were used. A total of 45 specimens - 15 specimens $(15 \times 1 \mathrm{~mm})$ for each cement were prepared according to ISO standard 4049:2009. The water sorptions of the cements were calculated by weighing the specimens before and after immersion and desiccation. Results. Nonparametric statistic methods were applied. GC Fuji Plus cement showed significantly higher values of water sorption in all three solutions of both resin cements $(\mathrm{p}<0.009)$ and significantly higher values of sorption in artificial saliva $\mathrm{pH} 3.0$. Multilink Automix showed significantly higher values of water sorption compared with Variolink II in artificial saliva $\mathrm{pH}$ 7.4, and higher values of sorption in this solution compared with $\mathrm{pH}$ value 3.0. Conclusion. Water sorption values are mainly influenced by the proportion of hydrophilic matrix, the type and composition of filler, and the $\mathrm{pH}$ value of solutions.
\end{abstract}

\section{Introduction}

Materials placed for long periods in the oral environment will undergo interaction with the oral fluids (1). Cements for permanent cementation must have the ability of long ageing in an environment such as the oral cavity, where, on the edge of the restoration area, cement is in contact with saliva, a fluid which contains organic and inorganic water soluble components (2).

The $\mathrm{pH}$ value of saliva is slightly alkaline. Food and liquids in the oral environment have various $\mathrm{pH}$ values and they can change the saliva's $\mathrm{pH}$ value $(3,4)$. Water sorption is important in evaluation of dental cement clinical durability. Water sorption and cement dissolution may result in decomposition of cement, which leads to debonding of the restoration, post-operative hypersensitivity, pulpal inflammation and periodontal disease (5-7). Water sorption leads to dimensional changes, loss of retention, color change and breaks in the margin contours, and it can also affect the mechanical properties of the cement, such as flexural strength, hardness and mechanical stability (8-10).

Numerous authors have pointed out that water may affect the bond strength between 
the dentin and the bonding agents. (11-14). Water sorption can lead to material discoloration and deterioration of the esthetic quality of the restoration (15). Resin-based cements constitute an important link in the adhesive luting technique in prosthodontics, but their water sorption behavior and dimensional change have not been sufficiently studied (6). In a moist environment, the polymer matrix of a resin-based cement can absorb water and swell, resulting in a decrease in elastic modulus and ultimate strength, and an increase in creep (16). Water sorption by polymers is a diffusion controlled process, and water uptake occurs mainly in the resin matrix (13). The water absorbed by the polymer matrix could cause filler-matrix debonding, or even hydrolytic degradation of the filler-resin interface (16). Hydrolytic degradation is a result of either the breaking of chemical bonds in the resin or softening, through the plasticizing action of water (17). The interaction between resin-based cements and water involves two opposing phenomena: the first is water sorption, which leads to the swelling of the material and an increase in weight, and the second is dissolution of materials (fillers or monomers) in the water, contributing to the shrinkage, weight, and reduction of the final specimens $(6,18)$.

As the luting agent for all ceramic restorations, resin-modified glass-ionomer ce- ment can be used, and it is also widely used for luting metal-ceramic crowns and cast post. Resin-modified glass-ionomer cement possesses the benefits of conventional glassionomer cements, such as fluoride release and adhesion to the tooth structure, along with the benefits of composite cement, such as improved strength, water sorption and solubility (19).

The objective of this research was to measure the water sorption of three cements for permanent cementation, in three different solutions: distilled water and artificial saliva of two different $\mathrm{pH}$ values, and to examine the influence of the $\mathrm{pH}$ value of the artificial saliva on water sorption. The null hypothesis was that there are no differences between the water sorption of different dental cements after immersion in three different solutions, and the $\mathrm{pH}$ value of artificial saliva has no influence on the water sorption of dental cements.

\section{Material and methods}

The cements used in this study are shown in Table 1.

Fifteen specimens of each cement were made according to ISO specification 4049:2009 (20). The specimens were made in Teflon molds of inner diameter $15 \pm 0.1$ $\mathrm{mm}$ and thickness $1 \pm 0.1 \mathrm{~mm}$. Preparation of specimens of self-curing GC Fuji Plus ce-

Table 1 Name, type and main component of cement

\begin{tabular}{|c|c|c|}
\hline Name of cement and manufacturer & Type of cement & Main components \\
\hline $\begin{array}{l}\text { GC Fuji PLUS CAPSULE (reinforced glass- } \\
\text { ionomer cement) GC Corporation Tokyo, } \\
\text { Japan. }\end{array}$ & $\begin{array}{l}\text { Resin-modified } \\
\text { glass-ionomer } \\
\text { cement. }\end{array}$ & $\begin{array}{l}\text { Powder: aluminofluorosilicate glass } \\
\text { Liquid: polyacrylic acid, HEMA, metadimethacrylate, water. }\end{array}$ \\
\hline $\begin{array}{l}\text { Multilink Automix IvoclarVivadent AG; } \\
\text { FL-9494 Schaan, Liechhtenstein. }\end{array}$ & Resin cement. & $\begin{array}{l}\text { Monomer: dimethacrylate, HEMA; Inorganic filler ( } 40 \%) \text { : } \\
\text { barium glass, ytterbium trifluoride, spheroid mixed oxide; } \\
\text { Additional content: catalysts, stabilizer, pigments. The mean } \\
\text { particle size is } 0.9 \mu \mathrm{m} \text {. }\end{array}$ \\
\hline $\begin{array}{l}\text { Variolink II } \\
\text { IvoclarVivadent AG; FL-9494 Schaan, } \\
\text { Liechhtenstein. }\end{array}$ & Resin cement. & $\begin{array}{l}\text { Monomer: Bis-GMA, urethane dimethacrylate, } \\
\text { triethylenglicoldimethacrylate; Inorganic filler ( } 40 \%) \text { : } \\
\text { barium glass, Ba-Al-fluorsilicate glass, ytterbium trifluoride, } \\
\text { spheroid mixed oxide; Additional content: catalysts, } \\
\text { stabilizers, pigments. The mean particle size is } 0.7 \mu \mathrm{m} \text {. }\end{array}$ \\
\hline
\end{tabular}


ment (GC Corporation Tokyo, Japan) was carried out as follows: a $50 \mu \mathrm{m}$ thick polyester film was put on a metal plate and over it the mold in which the cement was slightly overfilled, being careful to minimize air inclusion. Another polyester film was put on top of the material in the mold and was covered with a second metal plate to remove the excess material. The metal plates were bound together by clamps and the specimens were immediately stored in an incubator at $37 \pm 1^{\circ} \mathrm{C}$. After 60 minutes the specimens were removed from the mold. Specimens were trimmed and polished with 1000 grit silicon carbide grinding paper until the final diameter of $14.9 \pm 0.1 \mathrm{~mm}$ was attained. The diameter was measured with a TESA 0-25 mm micrometer for external measurements, with measurement accuracy of 0.001 mm (TESA, Renens, Switzerland).

For preparation of specimens of dual cure cements, the metal plate was replaced by a glass plate, over which polymerization of specimens was performed. The polymerization light was tested for light output by means of a digital radiometer (Bluephase Meter, Ivoclar Vivadent, Schaan, Liechtenstein). The tip of the polymerization lamp (Bluephase 20, Ivoclar Vivadent Ag, and FL-9494 Schaan, Liechtenstein) was directed over the center of the specimens for the correct time of exposure, and then eight peripheral overlapping sectors were irradiated for 20 seconds each, until the whole area had been irradiated. After that the lower side of the specimens was polymerized in the same way as the upper one. The specimens were immediately stored in an incubator at $37 \pm 1^{\circ} \mathrm{C}$ for 60 minutes, and then finished as the previous ones. After treatment was complete, all specimens were stored in desiccators with silicate gel, and the entire set was stored in an incubator maintained at $37 \pm 1^{\circ} \mathrm{C}$. After 22 hours the specimens were moved into another desiccator maintained at $23 \pm 1^{\circ} \mathrm{C}$ for 2 hours, and after that weighed on an analytical balance, Sartorius LE244S 0-240 g, accuracy of measurement 0.0001 g (Sartorius Göttingen, Germany) until a constant mass of $\mathrm{m} 1$ was obtained or until the mass loss of each specimen was not less than $0.01 \mathrm{mg}$ over $24 \mathrm{~h}$. The diameter-r $(\mathrm{mm})$ and thickness $\mathrm{h}(\mathrm{mm})$ of each specimen was measured by micrometer, with accuracy up to $0.001 \mathrm{~mm}$ according to the ISO specification, and the volume $\mathrm{V}\left(\mathrm{mm}^{3}\right)$ was calculated according to the formula: $\mathrm{V}=\pi \mathrm{x} \mathrm{r}^{2} \mathrm{xh}$.

Five specimens were immersed in distilled water, five specimens in artificial saliva $\mathrm{pH}$ value 7.4, and five specimens of each cement were immersed in artificial saliva $\mathrm{pH}$ value 3.0. All specimens were stored in a Culture Incubator (Ivoclar Vivadent, Schaan, Liechtenstein) at $37 \pm 1^{\circ} \mathrm{C}$ for 7 days. Tomasi's solution of artificial saliva $\mathrm{pH}$ value 7.4 was prepared for this research at the Department of Chemistry, Faculty of Natural Science and Mathematics of Sarajevo University (2).

In order to obtain a $\mathrm{pH}$-value of 3.0, Tomasi's solution was modified with the intentional acidification of the solution. After 7 days of storage all specimens were taken out of the liquid, washed with water, air dried for $15 \mathrm{~s}$ and weighed one minute after removal from the water to record the mass of the second cycle-m2. After weighing in the second cycle the specimens were again stored in the desiccator and incubator in the same way as in the initial cycle, and afterwards the mass - $m 3$, was recorded. The value of water sorption (Wsp) expressed in $\mathrm{mg} / \mathrm{mm}^{3}$ for each of the five specimens was calculated using the following formula (ISO 4049:2009): Wsp = $(\mathrm{m} 2-\mathrm{m} 3) / \mathrm{V}$, where: $\mathrm{m} 2=$ mass of specimens (mg) immersed in solution after 7 days, m3 $=$ mass of refined specimens $(\mathrm{mg})$ and $\mathrm{V}-$ volume of specimens $\left(\mathrm{mm}^{3}\right)$.

\section{Statistic methods}

All data were analyzed by the statistical software IBM SPSS v.17. Preliminary statisti- 
cal analyses were carried out to determine the distribution of dependent variables and make a decision on the application of parametric or nonparametric statistical methods. Since the dependent variables were asymmetric, the Mann-Whitney $U$ nonparametric statistical method was applied. As the required alpha level of significance for rejection of the null hypothesis, the level 0.05 (5\%) was taken. To avoid first category statistical error, in subsequent (Post hoc) sample comparisons, matching with Bonferroni was used, where the required alpha level of significance of $5 \%$ was corrected, i.e. divided by the comparison number $(\mathrm{p}<0.05 / 3$ $=\mathrm{p}<0.017)$.

\section{Results}

The arithmetical mean and standard deviations of water sorption for each dental cement in the three different solutions are shown in Table 2. A difference in water sorption levels between the cements GC Fuji Plus and Variolink II; $\mathrm{p}=0.009$ (effect size $=0.826$ ), and GC Fuji Plus and Multilink Automix; $p=0.009$ (effect size $=0.826$ ), in all three solutions was confirmed. Multilink Automix showed a statistically significant difference in water sorption; $\mathrm{p}=0.009$ (effect size $=0.826$ ), in comparison with Variolink II in a solution of artificial saliva $\mathrm{pH}$ 7.4. Post hoc comparisons are shown in Table 3. Sta-

Table 2 Mean and Standard Deviation of water sorption between groups

\begin{tabular}{|c|c|c|c|c|}
\hline Water sorption in different solutions & Type of cement & $\mathrm{n}$ & Mean & SD \\
\hline \multirow[t]{2}{*}{ Water sorption (m2-m3)/V1 - distilled water } & GC Fuji Plus & 5 & 181.50 & 5.17 \\
\hline & Variolink II & 5 & 15.74 & 0.84 \\
\hline \multirow{3}{*}{ Water sorption (m2-m3)/V1 - in artificial saliva pH 7.4} & Multilink Automix & 5 & 21.30 & 0.49 \\
\hline & GC Fuji Plus & 5 & 173.72 & 4.66 \\
\hline & Variolink II & 5 & 15.87 & 0.21 \\
\hline \multirow{3}{*}{ Water sorption (m2-m3)/V1 - in artificial saliva pH 3.0} & Multilink Automix & 5 & 19.31 & 2.09 \\
\hline & GC Fuji Plus & 5 & 185.81 & 4.61 \\
\hline & Variolink II & 5 & 15.19 & 2.70 \\
\hline
\end{tabular}

Table 3 Post hoc comparison between groups

\begin{tabular}{|c|c|c|c|}
\hline \multirow{2}{*}{ Type of cement } & Multilink Automix & GC Fuji Plus & Variolink II \\
\hline & \multicolumn{3}{|c|}{ Water sorption $(\mathrm{m} 2-\mathrm{m} 3) / \mathrm{V} 1$ - distilled water } \\
\hline Multilink Automix & - & $\mathrm{p}=0.009(0.826)$ & NS \\
\hline GC Fuji Plus & $\mathrm{p}=0.009(0.826)$ & - & $\mathrm{p}=0.009(0.826)$ \\
\hline \multirow[t]{2}{*}{ Variolink II } & NS & $\mathrm{p}=0.009(0.826)$ & - \\
\hline & \multicolumn{3}{|c|}{ Water sorption $(\mathrm{m} 2-\mathrm{m} 3) / \mathrm{V} 1$ - in artificial saliva $\mathrm{pH} 7.4$} \\
\hline Multilink Automix & - & $\mathrm{p}=0.009(0.826)$ & $p=0.009(0.826)$ \\
\hline GC Fuji Plus & $\mathrm{p}=0.009(0.826)$ & - & $0.009(0.826)$ \\
\hline \multirow[t]{2}{*}{ Variolink II } & $\mathrm{p}=0.009(0.826)$ & $\mathrm{p}=0.009(0.826)$ & - \\
\hline & \multicolumn{3}{|c|}{ Water sorption (m2-m3)/V1 - in artificial saliva pH 3.0} \\
\hline Multilink Automix & - & $\mathrm{p}=0.009(0.826)$ & NS \\
\hline GC Fuji Plus & $\mathrm{p}=0.009(0.826)$ & - & $\mathrm{p}=0.009(0.826)$ \\
\hline Variolink II & NS & $\mathrm{p}=0.009(0.826)$ & - \\
\hline
\end{tabular}

Mann Whitney $\mathrm{U}$ test ; $\mathrm{p}($ effect size $=\mathrm{Z} / \sqrt{ } \mathrm{n}$ ); NS=not statistically significant. 
Table 4 Post hoc comparison between groups

\begin{tabular}{lll}
\hline \multirow{2}{*}{ Solutions } & A.S. $\mathrm{pH} 7.4$ & A.S. $\mathrm{pH} 3.0$ \\
\cline { 2 - 3 } & Multilink Automix & \\
\hline A.S. $\mathrm{pH} 7.4$ & - & $\mathrm{p}=0.009(0.826)$ \\
\hline A.S. $\mathrm{pH} 3.0$ & $\mathrm{p}=0.009(0.826)$ & - \\
\hline & GC Fuji Plus & $\mathrm{p}=0.016(0.759)$ \\
\hline A.S. $\mathrm{pH} 7.4$ & - & - \\
\hline A.S. $\mathrm{pH} 3.0$ & $\mathrm{p}=0.016(0.759)$ & \\
\hline
\end{tabular}

Mann Whitney $\mathrm{U}$ test; $\mathrm{p}$ (effect size $=\mathrm{Z} / \sqrt{ } \mathrm{n}$ ); NS=not statistically significant.

tistical analysis of the effect of $\mathrm{Ph}$ value on the water sorption of dental cements confirmed a statistically significant difference $\mathrm{p}=0.009$ (effect size $=0.826$ ), in water sorption in Multilink Automix cement between the solution of artificial saliva $\mathrm{pH}$ value 7.4 and artificial saliva $\mathrm{pH}$ value 3.0. Post hoc comparisons are shown in Table 4.

A statistically significant difference, $\mathrm{p}=0.016$ (effect size $=0.759$ ), in the levels of water sorption for GC Fuji Plus cement was confirmed between the solutions of artificial saliva $\mathrm{pH} 7.4$ and artificial saliva $\mathrm{pH}$ 3.0 (Table 4). Studying the effect of $\mathrm{pH}$ value on the water sorption of Variolink II dental cement, in this case we did not find any statistically significant difference in the levels of water sorption with cement Variolink II between the different solutions, with a probability of $\mathrm{p}=0.248$.

\section{Discussion}

The resin modified glass ionomer (GC Fuji Plus) cement tested in this study exhibited statistically significant higher water sorption in relation to the composite cements in all three solutions. Resin-modified glass-ionomer had a dual setting reaction, involving mainly an acid-base reaction and free radical polymerization. The polymerized structure of resin-modified glass-ionomer cement contains a high percentage of hydrophilic functional groups in a well-networked matrix, and it may be similar to synthetic hydro gels. Synthetic hydro gels are often prepared from HEMA copolymer and are designed to hold huge amounts of water, possibly up to $80 \%$ of their mass (5). Materials which have more HEMA in their composition will have higher water sorption. As GC Fuji Plus cement contains HEMA in its composition, it is considered that this is the main reason for the statistically significantly greater water sorption in this material in relation to both the composite cements in all three solutions. The presence of hydroxyl ethyl methacrylate (HEMA) was the main reason for the hygroscopic expansion, which leads to retention stress on the tooth and restoration, and could result in postoperative sensitivity (6, $21)$. The clinical implication of this examination shows that these cements, because of their significant dimensional changes, are not applicable for cementing all ceramic restorations and composite posts, because their expansion may eventually result in the fracture of the restoration or tooth root (22-24). One must be careful with cementing a post in the very thin walls of the tooth root canal.

Our data agree with the data of Beriat (25), Messe (6), Gordole (26) and Mortier (15). In Gerdolea's research, GC Fuji Plus showed some higher values of water sorption than in this research, and this could be explained by the fact that mechanically mixed capsulated cement was used in this research, while Gerdole used hand mixed cement. The manual mixing process can lead to the formation of air voids that 
can accelerate water sorption by increasing the surface area exposed to the water and, at the same time, sorption (18, 27-29). Although resin-modified glass-ionomer cement showed significantly higher sorption than resin cements, those values are lower compared with conventional luting cements. The best choice of cement for cementing metal-ceramic restorations is resin-modified glass- ionomer cements, due to the fact that they have other characteristics which are superior in comparison with conventional cements.

There is not a large amount of data in the literature about the effect of $\mathrm{pH}$ value on the water sorption of resin-modified glass-ionomer cements. Fano et al. suggest that the decrease in $\mathrm{pH}$ value accelerates erosion by increasing the number of micro cracks (30). Specimens with more micro cracks will absorb more water, so the water sorption of CG Fuji Plus cement was significantly higher in artificial saliva with lower $\mathrm{pH}$ values. Hydrolytically, degradation which resulted in water sorption is based on micro cracks appearing in the acidic environment. Czarnecka confirms that water sorption depends on the solution composition, and that increases in lactic acid resulting in formation of erosion (31).

There was a small amount of water sorption in the resin cements. Water sorption by polymers is a controlled process of diffusion which mainly takes place in the resin matrix $(15,16,18)$. The sorption depends on the resin composition, which is determined by hydrophilicity, mobility kinetic parameters, and filler content $(18,32)$. The presence of hydroxyl, carboxylic and phosphate groups in monomers and polymers makes them more hydrophilic. The resulting polymers are not considered to be extremely hydrophilic, but nevertheless they will absorb water (33). The water sorption which occurred in Variolink II may be explained by the BisGMA monomer in its composition, which contains pendant hydroxyl groups within its molecular structure (34). Mese (6) and Gordole (26) obtained results for Variolink II in samples stored in water which correspond with this research. HEMA flows more easily in water than Bis-GMA because of its lower molecular weight and hydrophilic chemical structure. It contains hydroxyl groups with a high affinity for hydrogen bonds (35), which can explain the slightly higher arithmetic mean of water sorption of Multilink Automix cement in comparison with Variolink II in all three solutions, and by the Mann Whitney U-test, Multilink Automix showed a statistically significant difference in comparison with Variolink II in the solution of artificial saliva with a $\mathrm{pH}$ value of 7.4. The results for resin cement corresponded with the results of Mese (6), Gordole (26), Vrochari (36), and the results which Mortier (15), Malacarne (9), Ortengren (13) and Berger (37) obtained for composite restorative materials. Taking into account the fact that the $\mathrm{pH}$ value changes constantly in the oral environment, it seems that dental composites are designed to endure acidic conditions $(38,39)$. The effect of the alkaline medium on composite properties explained its interaction with $\mathrm{OH}$-ions during the process of hydrolysis. Accelerated degradation is expected in a medium with an excess of hydroxyl ions. Besides the possibility of debonding, hydrolysis of the filler may occur (38). This may explain the statistically significant difference in water sorption levels in Multilink Automix cement between the solutions of artificial saliva with $\mathrm{pH}$ values of 7.4 and 3.0. It must be pointed out that the level of water sorption of Multilink Automix in artificial saliva 7.4 is lower than the maximum water sorption value $(40 \mathrm{mg} /$ $\mathrm{mm}^{3}$ according to ISO specification 4049). As is the case with most in vitro studies, caution must be used when the results are extrapolated to the oral environment. The solution of artificial saliva used in our re- 
search did not consist of enzymes, therefore higher water sorption could be expected in the mouth, because they may lead to degradation, which would be expressed in reality because of the anhydrase, amylase, peroxidase, lysozumes and other esterases, which can cause less resistance in materials based on resin $(40,41)$. If the material is exposed to enzymes for a long time, degradation of the surface may be the result of the acidic products of bacteria (33). Curing specimens in vitro represents an ideal processing procedure (29). In the complex oral environment, maximum polymerization cannot be expected, which can result in a reduction in the mechanical properties of the cement, increasing micro leakage, post-operative sensitivity, secondary caries and aesthetic failure $(42,43)$. Therefore, higher sorption than the reported values is expected because of incomplete polymerization in the oral cavity.

Aesthetic dentistry composite cements are becoming increasingly used in clinical practice for permanent cementing of porcelain veneers, all ceramic crowns, inlays, onlays and composite posts. Resin modified cement can be used for cementing all ceramic restorations and it is also widely used for luting metal-ceramic crowns and cast posts. Multilink Automix, Variolink II, GC Fuji Plus were selected because there are commonly used in our clinical practice. The composite cements showed the best mechanical properties of all luting cements. One shortcoming is that the clinical procedure is more complicated (44). New types of cements have been developed such as selfetching composite cements for reducing the multiple clinical steps required for application of the composite cement. Nevertheless, self-etching composite cements simultaneously demineralize and infiltrate the tooth substrate $(44,45)$. Some future studies could examine self-adhesive composite cements for luting of prostodontic restorations.
In this study, the water sorption of a material was assessed in distilled water over a one-week period, according to the ISO standard 4049. Müller et al. concluded that water sorption according to ISO 4049 provides reliable results (46). Some studies have shown that polymeric materials absorb water continuously over a long period of time $(6,47)$. A future study could be extended to a longer period of time, such as 30,90 , and 180 days, and one year of the specimens being immersed in water.

\section{Conclusion}

The resin modified glass-ionomer cement Fuji Plus showed the significantly highest water sorption values in all three examined solutions, and did not satisfy Standard 4049. Multilink Automix and Variolink II were found to comply with ISO requirements regarding water sorption. The values of water sorption of cements were found to depend on the matrix hydrophilicity, type and composition of the filler. The $\mathrm{pH}$ value of saliva affected the water sorption of dental cements.

\section{What is already known on this topic \\ Water absorption is an important factor in the evaluation of the clinical durability of dental cements. Knowing the cement's material properties will enable the appropriate choice of ce- ment for permanent cementation and the durability of fixed prosthetic restoration.}

\section{What this study adds}

There are numerous studies of water absorption in dental cements while studies with artificial saliva are rare. This research contributes to the knowledge about water absorption in artificial saliva with various $\mathrm{pH}$ values.

Acknowledgments: We thank GC EEO (Bosnia \& Herzegovina) and Ivoclar Vivadent AG (Schaan Liechtenstein) for material support. Special thanks to the Institute of Metrology of Bosnia and Herzegovina, Laboratory for Mass as well as the Department of Chemistry, Faculty of Natural Sciences and Mathematics, University of Sarajevo, for measuring and preparing the solutions. 
Authors' contributions: Conception and design: AGG and SK; Acquisition, analysis and interpretation of data: SZ, SSP, AKĆ and MA; Drafting the article: SK and AGG; Revising it critically for important intellectual content: SSP, SZ and AKĆ; Approved final version of the manuscript: AGG and MA.

Conflict of interest: The authors declare that they have no conflict of interest.

Sources of support: We had material support from GC EEO (Bosnia \& Herzegovina) and Ivoclar Vivadent AG (Schaan Liechtenstein). We had support in measuring and solution preparation from the Institute of Metrology of Bosnia and Herzegovina, Laboratory for Mass and well as the Department of Chemistry, Faculty of Natural Sciences and Mathematics, University.

\section{References}

1. McCabe JF, Rusby S. Water absorption, dimensional change and radial pressure in resin matrix dental restorative materials. Biomaterials. 2004;25(18):4001-7.

2. Preetha A, Banerjee R. Comparison of artificial saliva substitutes. Trends Biomater Artif Organs. 2005;18(2):178-86.

3. Greabu M, Battino M, Mohora M, Totan A, Didilescu A, Spinu T, et al. Saliva diagnostic window to the body, both in health and in disease. J Med Life. 2009;2(2):124-32.

4. Borjian A, Ferrari CC, Anouf A, Touvz LZ. Popcola acids and tooth erosion: an in vitro, in vivo, electron-microscopic, and clinical report. Int J Dent. 2010;2010:957842.

5. Kanchanavasita W, Anstice HM, Pearson GJ. Water sorption characteristics of resin-modified glassionomer cements. Biomaterials. 1997;18(4):343-9.

6. Mese A, Burow MF, Tyas MJ. Sorption and solubility of luting cements in different solutions. Dent Mater J. 2008;27(5):702-9.

7. Piwowarczyk A, Lauer HC, Sorensen JA. Microleakage of various cementing agents for full cast crowns. Dent Mater. 2005;21(5):445-53.

8. Cattani-Lorente MA, Dupuis V, Payan J, Moya F, Meyer JM. Effect of water on the physical properties of resin-modified glass-ionomer cements. Dent Mater. 1999;15(1):71-8.

9. Musanje L, Shu M, Darvell BW. Water sorption and mechanical behavior of cosmetic direct restorative materials in artificial saliva. Dent Mater. 2001;17(5):394-401.
10. Malacarne J, Carvalho RM, De Goes MF, Svirzero N, Pashley $\mathrm{DH}$, Tay F, et al. Water sorption/ solubility of dental adhesive resins. Dent Mater. 2006;22(10):973-80.

11. Chaves CA, De Melo RM, Passos SP, Camargo FP, Bottino MA, Balducci I. Bond strength durability of self-etching adhesives and resin cements to dentin. J Appl Oral Sci. 2009;17(3):155-60.

12. Danphal P, Yiu CK, King NM, Tay FR, Hiraishi N. Effect of temperature on water sorption and solubility of dental adhesive resins. J Dent. 2009;37(2):122-32.

13. Ortengren U, Wellendorf H, Karlsson S, Ruyter IE. Water sorption and solubility of dental composites and identification of monomers released in an aqueous environment. J Oral Rehabil. 2001;28(12):1106-15.

14. Garcia RN, de Goes MF, Giannini M. Effect of water storage on bond strength of self-etching adhesives to dentin. J Contemp Dent Pract. 2007;8(7):46-53.

15. Mortier E, Gerdolle DA, Jacquot B, Panighi MM. Importance of water sorption and solubility studies for couple bonding agent-resin-based filling material. Oper Dent. 2004;29(6):669-76.

16. Ortengren U, Elgh U, Spasenoska V, Milleding P, Haasum J, Karlsson S. Water sorption and flexural properties of a composite resin cement. Int J Prosthodont. 2000;13(2):141-7.

17. Mohsen NM, Craig RG. Hydrolytic stability of silanated zirconia-silica-urethane dimethacrylate composites. J Oral Rehabil. 1995;22(3):213-20.

18. Toledano M, Osorio R, Osorio E, Fuentes V, Prati C, Garcia-Godoy F. Sorption and solubility of resinbased restorative dental materials. J Dent. 2003;31(1):43-50.

19. Knobloch LA, Kerby RE, McMillen K, Clelland N. Solubility and sorption of resin-based luting cements. Oper Dent. 2000;25(5):434-40.

20. International organization for standardization. Technical Committee: ISO/TC 106/SC 1. Dentistry-Polymer-Based Restorative Materials (ISO 4049). 4th ed. Geneva: International organization for standardization; 2009.

21. Oyague RC, Monticelli F, Toledano M, Osorio E, Ferrari M, Osorio R. Effect of water aging on microtensile bond strength of dual-cured resin cements to pre-treated sintered zirconium-oxide ceramics. Dent Mater. 2009;25(3):392-9.

22. Diaz-Arnold AM, Vargas MA, Haselton DR. Current status of luting agents for fixed prosthodontics. J Prosthet Dent. 1999;81(2):135-41.

23. Behr M, Rosentritt M, Mangelkramer M, Handel G The influence of different cements on the fracture resistance and marginal adaptation of all ce- 
ramic and fiber-reinforced crowns. Int J Prosthodont. 2003;16(5):538-42.

24. Leevailoj C, Platt JA, Cochran MA, Moore BK. In vitro study of fracture incidence and compressivefracture load of all-ceramic crowns cemented with resin-modified glass- ionomer and other luting agents. J Prosthet Dent. 1998;80(6):699-707.

25. Beriat NC, Nalbant D. Water Absorption and HEMA Release of Resin-Modified Glass-Ionomers. Eur J Dent. 2009;3(4):267-72.

26. Gerdolle DA, Mortier E, Jacquot B, Panighi MM. Water sorption and water solubility of current luting cements: an in vitro study. Quintessence Int. 2008;39(3):107-14.

27. Lygre H, HolPJ, SolheimE, MoeG. Organic leachable from polymer-based dental filling materials. Eur J Oral Sci. 1999;107(5):378-83.

28. Miguel A, de la Macorra JC, Nevado S, Gómez J. Porosity of resin cements and resin-modified glass-ionomers. Am J Dent. 2001;14(1):17-21.

29. Malkoç MA, Sevimay M, Tatar İ, Çelik HH. MicroCT Detection and Characterization of Porosity in Luting Cements. J Prosthodont. 2015;24(5):55361.

30. Fano L, Fano V, Ma W, Wang X, Zhu F. Hydrolytic degradation and cracks in resin-modified glassionomer cements. J Biomed Mater Res B Appl Biomater. 2004;69(1):87-93.

31. Czarnecka B, Nicholson JW. Ion release by resinmodified glass-ionomer cements into water and lactic acid solutions. J Dent. 2006;34(8):539-43.

32. Giti R, Vojdani M, Abduo J, Bagheri R. The Comparison of Sorption and Solubility Behavior of Four Different Resin Luting Cements in Different Storage Media. J Dent (Shiraz). 2016;17(2):91-7.

33. Ferracane J. Hygroscopic and hydrolytic effects in dental polymer networks. Dent Mater. 2006;22(8):211-22.

34. Kerby RE, Knobloch LA, Schricker S, Gregg B. Synthesis and evaluation of modified urethane dimethacrylate resins with reduced water sorption and solubility. Dent Mater. 2009;25(3):302-13.

35. Moreira FCL, Antoniosi Filho NR, Souza JB, Lopes LG. Sorption, solubility and residual mono- mers of a dental adhesive cured by different lightcuring units. Braz Dent J. 2010;21(5):432-8.

36. Vrochari AD, Eliades G, Hellwig E, Wrbas KT. Water sorption and solubility of four self-etching, self-adhesive resin luting agents. J Adhes Dent. 2010;12(1):39-43.

37. Berger BS, Palialol ARM, Cavalli V, Giannini M. Characterization of water sorption, solubility and filler particles of light-cured composite resins. Braz Dent J. 2009;20(4):314-8.

38. Prakki A, Cilli R, Mondelli RF, Kalachandra S, Pereira JC. Influence of $\mathrm{pH}$ environment on polymer based dental material properties. J Dent. 2005;33(2):91-8.

39. Buchalla W, Attin T, Hellwig E. Brushing abrasion of luting cements under neutral and acidic conditions. Oper Dent. 2000;25(6):482-7.

40. Soderholm KJM, Mukherjee R, Longmate J. Filler leach ability of composites stored in distilled water or artificial saliva. J Den Res. 1996;75(9):1692-9.

41. Finer Y, Santerre JP. The influence of resin chemistry on a dental composite's biodegradation. J Biomed Mater Res A. 2004;69(2):233-46.

42. Felix CA, Price RB. The effect of distance from light source on light intensity from curing lights. J Adhes Dent. 2003;5(4):283-91.

43. Galvão MR, Caldas SG, Bagnato VS, de Souza Rastelli AN, de Andrade MF. Evaluation of degree of conversion and hardness of dental composites photo-activated with different light guide tips. Eur J Dent. 2013;7(1):86-93.

44. Marghalani H.Y. Sorption and solubility characteristics of self-adhesive resin cements. Dent Mater. 2012;28(10):187-98.

45. Kim HJ, Bagheri R, Kim YK, Son JS, Kwon TY. Influence of Curing Mode on the Surface Energy and Sorption/Solubility of Dental Self-Adhesive Resin Cements. Materials (Basel). 2017;10(2):129.

46. Müller JA, Rohr N, Fischer J. Evaluation of ISO 4049: Water sorption and water solubility of resin cements. Eur J Oral Sci. 2017;125(2):141-50.

47. Walter R, Feiring AE, Boushell LW, Braswell K, Bartholomew W, Chung Y, et al. One-year water sorption and solubility of "all-in-one"adhesives. Braz Dent J. 2013;24(4):344-8. 